\title{
Priority areas for cannabis and cannabinoid product research in South Africa
}

\begin{tabular}{|c|c|}
\hline Authors: & cting 1 \\
\hline $\begin{array}{l}\text { Tanya N. Augu } \\
\text { Carel J. Cairns }\end{array}$ & ustine ${ }^{1}$ (1) \\
\hline Sean Chetty ${ }^{3}$ & \\
\hline Lisa G. Dannat & $\mathrm{tt}^{4}$ (1) \\
\hline $\begin{array}{l}\text { Nadine Grave } \\
\text { Glenda Grey }\end{array}$ & $\mathrm{tt}^{1}$ (1) \\
\hline Gerhard Grob & $\operatorname{ler}^{6}$ (1) \\
\hline Zukiswa Jafta ${ }^{7}$ & \\
\hline Peter Kamerm & $\mathrm{han}^{8,9}$ (1) \\
\hline John Lopes ${ }^{10}$ & \\
\hline Motlalepula G & i. Matsabisa ${ }^{11}$ (1) \\
\hline Pierre Mugab & $\mathrm{O}^{12}$ (1) \\
\hline Michelle Mulc & $\operatorname{der}^{13}$ \\
\hline Charles Parry ${ }^{1}$ & 14,15 (c) \\
\hline Solomon Rata & emane ${ }^{16}$ (1) \\
\hline Nandi Siegfrie & $\mathrm{d}^{14,17}$ \\
\hline Vanessa Steen & 1kamp ${ }^{18}$ (1) \\
\hline Eileen Thoma & $\mathrm{s}^{19}$ (1) \\
\hline Richard van Z & $\mathrm{yl}-\mathrm{Smit}^{20}$ (1) \\
\hline Affiliations: & \\
\hline${ }^{1}$ School of Anc & atomical \\
\hline Sciences, Facu & ulty of Health \\
\hline Sciences, Univ & versity of the \\
\hline Witwatersran & d, South Africa \\
\hline${ }^{2}$ Department $\mathrm{C}$ & \\
\hline $\begin{array}{l}\text { Anaesthesia, } \\
\text { Pietermaritzbu }\end{array}$ & $\begin{array}{l}\text { Grey's Hospital, } \\
\text { urg, South Africa }\end{array}$ \\
\hline${ }^{3}$ Department & \\
\hline Anaesthesiolo & gy and Critical \\
\hline Care, Faculty & of Medicine and \\
\hline Health Scienc & es, Stellenbosch \\
\hline University, So & uth Africa \\
\hline $\begin{array}{l}{ }^{4} \text { Department } \\
\text { and Mental H } \\
\text { Health Scienc } \\
\text { Cape Town, Sc }\end{array}$ & $\begin{array}{l}\text { of Psychiatry } \\
\text { ealth, Faculty of } \\
\text { es, University of } \\
\text { outh Africa }\end{array}$ \\
\hline $\begin{array}{l}{ }^{5} \text { South African } \\
\text { Research Cou } \\
\text { South Africa }\end{array}$ & $\begin{array}{l}\text { Medical } \\
\text { ncil, Cape Town, }\end{array}$ \\
\hline $\begin{array}{l}{ }^{6} \text { Department } \\
\text { Faculty of Hea } \\
\text { University of } \\
\text { South Africa }\end{array}$ & $\begin{array}{l}\text { Psychiatry, } \\
\text { alth Sciences, } \\
\text { Pretoria, }\end{array}$ \\
\hline $\begin{array}{l}{ }^{7} \text { Frere Hospita } \\
\text { South Africa }\end{array}$ & l, East London, \\
\hline Read online: & \\
\hline 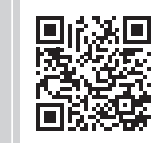 & $\begin{array}{l}\text { Scan this QR } \\
\text { code with your } \\
\text { smart phone or } \\
\text { mobile device } \\
\text { to read online. }\end{array}$ \\
\hline
\end{tabular}

The legalisation of cannabis for medicinal use is a contentious space both politically and in the medical community. In 2014, the Medical Innovation Bill introduced by Mario Oriani-Ambrosini MP, aimed to shift the political and legal positions of cannabis as an illegal substance to one available for research and medical use. To date, progress on this has been slow. Cannabis and cannabinoid products are currently available for medicinal use in several countries, including the Netherlands and 29 states in the United States. Locally, anecdotal reports suggest that many of our patients with chronic medical conditions are using cannabis and cannabis-derived or cannabinoid products for symptom alleviation.

In January 2016, the Alcohol, Tobacco and Other Drug Research Unit (ATODRU) of the South African Medical Research Council (SAMRC) produced a policy brief evaluating the findings of a published systematic review of current evidence to inform the discussion. ${ }^{1,2}$ The review identified moderate quality evidence to support the use of medicinal cannabis for chronic pain, chemotherapy-induced nausea, vomiting, and multiple sclerosis, ${ }^{1,2}$ but the many formulations, dosages and routes of administration limit recommendations.

Subsequently, the SAMRC brought key stakeholders representing all nine faculties of health sciences at South African universities together on 08 February 2017 at the SAMRC Medicina Campus, Cape Town, to explore opportunities for conducting local research and clinical trials of medicinal cannabis and cannabinoids to inform local policy-making. The workshop identified three major research priorities:

- Conduct a national, multisite clinical trial of cannabinoids following identification of the optimal formulations, dosage and relevant clinical indications from the current evidence base to inform trial protocol development.

- Support exploratory research to quantify the prevalence and qualify the current use of extracts (e.g. oils) in the community to alleviate pain and other symptoms; methods to include are as follows, (1) community- or clinic-based cross-sectional surveys or online survey of general public, (2) cross-sectional surveys of practising general practitioners and/or specialists in pain clinics with respect to their knowledge of patient use of cannabis extracts through patient disclosure.

- Conduct qualitative evaluation(s) of possible barriers and facilitators to medical practitioners prescribing cannabis or cannabinoids for medicinal purposes, should it be legalised in the future.

Further to this meeting, an SAMRC-supported team of researchers evaluated the evidence for a trial of a cannabinoid for the management of pain related to HIV associated sensory neuropathy

\footnotetext{
${ }^{8}$ Brain Function Research Group, Faculty of Health Sciences, University of the Witwatersrand, South Africa ${ }^{9}$ School of Biomedical Sciences, Curtin University, Australia

${ }^{10}$ Department of Biomedical Sciences, Faculty of Medicine and Health Sciences, Stellenbosch University, South Africa

${ }^{11}$ Department of Pharmacology, Faculty of Health Sciences, University of Free State, South Africa

${ }^{12}$ School of Pharmacy, Faculty of Natural Sciences, University of the Western Cape, South Africa

${ }^{13}$ Grants Innovation and Product Development, Strategic Health Innovation Partnerships, South African Medical Research Council, South Africa

${ }^{14}$ Alcohol and Tobacco and Other Drug Research Unit, South African Medical Research Council, South Africa

${ }^{15}$ Department of Psychiatry, Faculty of Medicine and Health Sciences, Stellenbosch University, South Africa

${ }^{16}$ Department of Psychiatry, School of Medicine, Sefako Makgatho Health Sciences University, South Africa

${ }^{17}$ Department of Psychiatry and Mental Health, Faculty of Health Sciences, University of Cape Town, South Africa

${ }^{18}$ Department of Pharmacology, Faculty of Health Sciences, University of Pretoria, South Africa

${ }^{19}$ Department of Psychiatry, Faculty of Medicine and Health Sciences, Stellenbosch University, South Africa

${ }^{20}$ Lung Institute and Division of Pulmonology, Faculty of Health Sciences, University of Cape Town, South Africa

Corresponding author: Nandi Siegfried, nandi.siegfried@gmail.com

How to cite this article: Augustine TN, Cairns CJ, Chetty S, et al. Priority areas for cannabis and cannabinoid product research in South Africa. Afr J Prm Health Care Fam Med. 2018;10(1), a1711. https://doi.org/10.4102/phcfm.v10i1.1711
}

Copyright: (C) 2018. The Authors. Licensee: AOSIS. This work is licensed under the Creative Commons Attribution License. 
(HIV-SN). The team selected painful HIV-SN as the condition based on: (1) the high burden of HIV and HIV-SN in the South African population, despite availability of improved antiretroviral drug regimens, and (2) the absence of empirical evidence supporting the efficacy of pharmacological agents typically recommended for the management of neuropathic pain in this population group. They limited their assessment to high-quality trials of greater than 12 weeks duration, included participants with at least moderate intensity pain at baseline and who met current recommendations for trial design in the field of chronic pain. ${ }^{3}$ Only three studies, all using a fixed dose combination of tetrahydrocannabinol (THC) and cannabidiol (CBD) delivered via oromucosal spray were identified, and the results of the GRADE ${ }^{4}$ assessment are shown in Table 1.

The team concluded that clinical equipoise ${ }^{5}$ exists for a fixed dose THC:CBD oromucosal cannabinoid spray trial for the management of painful HIV-SN. This was based on the GRADE assessment, the absence of demonstrably effective alternative therapies for painful HIV-SN and the clinical need in people living with HIV. The team is currently working on a study protocol for a multisite trial that conforms with the current highest standards for trials of analgesic agents for chronic pain. 3,5 The SAMRC will be releasing a Request for Applications (RFA) from groups interested in participating in trials in due course.

In medical practice, there is a balance between early adoption of new innovation and a slower, more considered approach prioritising evidence and safety over potential benefit. Though there are some clear areas where evidence supports the use of medicinal cannabis (as reviewed in the SAMRC policy brief), this should not imply that cannabis is a panacea for all ails or that it should be freely available without due control of production quality, disease indications and specific dosing recommendations. Research is urgently needed and regulatory changes will promote and allow for high priority, locally relevant research using regionally sourced products.

It is imperative that the medical and scientific community both practitioners and researchers - are involved in informing and developing evolving cannabis policies. Much confusion exists between medical versus recreational usage, the legal statutes of medical and recreational possession and usage, and the scientific evidence compared to impassioned anecdotal reports of its efficacy in addressing a host of medical conditions. We owe it to our patients to offer the best relief of suffering with all available therapies based on the rational assessment of benefit, cost and potential harms of cannabis and cannabinoid products for medicinal use.

\section{Acknowledgements}

The authors thank the South African Medical Research Council (SAMRC) Alcohol, Tobacco and Other Drug Research Unit, and the SAMRC Strategic Health Innovation 
Partnerships Division for their financial and administrative support.

\section{Competing interests}

The authors declare that they have no financial or personal relationships that may have inappropriately influenced them in writing this article.

\section{Authors' contributions}

All authors are members of the South African Cannabis Network and provided input to and/or attended an SAMRC Workshop held in February 2017 on which this article is based. All authors contributed to the draft manuscript. S.C., P.K. and N.S. developed the GRADE table. R.V.Z.S. and C.P. led the revision of the final manuscript.

\section{References}

1. Siegfried N, Parry C, Myers B. Cannabinoids for medicinal use 2016 [homepage on the Internet]. [cited 2017 Nov 17]. https://www.health-e.org.za/wp-content/ uploads/2016/01/Cannabinoids.pdf

2. Whiting PF, Wolff RF, Deshpande $S$, et al. Cannabinoids for Medical Use: A systematic review and meta-analysis. JAMA. 2015;313:2456-2473. https://doi. org/10.1001/jama.2015.6358

3. Dworkin RH, Turk DC, Peirce-Sandner S, et al. Considerations for improving assay sensitivity in chronic pain clinical trials: IMMPACT recommendations. Pain. 2012;153:1148-1158. https://doi.org/10.1016/j.pain.2012.03.003

4. Guyatt $G H$, Oxman $A D$, Vist GE, et al. GRADE: An emerging consensus on rating quality of evidence and strength of recommendations. BMJ. 2008;336:924-926. https://doi.org/10.1136/bmj.39489.470347.AD

5. Hey SP, Truog RD. The question of clinical equipoise and patients' best interests AMA J Ethics. 2015;17:1108-1115. https://doi.org/10.1001/journalofethics.2015. 17.12.ecas1-1512

6. Langford RM, Mares J, Novotna A, et al. A double-blind, randomized, placebocontrolled, parallel-group study of THC/CBD oromucosal spray in combination with the existing treatment regimen, in the relief of central neuropathic pain in patients with multiple sclerosis. J Neurol. 2013;260(4):984-997. https://doi.org/ 10.1007/s00415-012-6739-4

7. Serpell M, Ratcliffe S, Hovorka J, et al. A double-blind, randomized, placebo-controlled, parallel group study of THC/CBD spray in peripheral neuropathic pain treatment. Eur Pain. 2014;18(7):999-1012. https://doi.org/10.1002/j.1532-2149.2013.00445.x 